\title{
La mercadotecnia social como mecanismo de presión para ser Empresa Socialmente Responsable
}

\author{
Social marketing as a pressure mechanism \\ to be a Socially Responsible Company
}

Alejandra Patricia Arroyo Cuevas* UNITEC

Ermita Iztapalapa núm. 557, Col. Granjas Esmeralda, Iztapalapa, C.P. 09810, Ciudad de México, México

Editor: Rogelio del Prado Flores

Fecha de recepción: 31 de julio de 2020

Fecha de aceptación: 3 de noviembre de 2020 alejandrapatricia_arroyo@hotmail.com http://orcid.org/0000-0001-8695-6916\#sthash.jFACzUZT.dpuf

\section{RESUMEN}

El fenómeno de la globalización, que tuvo su momento de expansión y consolidación en los años noventa, generó graves problemáticas cuyas nefastas consecuencias fueron daños al medio ambiente, prácticas comerciales abusivas, invasión de maquiladoras en países pobres donde la fuerza laboral no tenía un lugar fijo donde vivir ni derechos y se les pagaba menos de un dólar diario. Pero también los países desarrollados de donde salieron las fábricas sufrieron estragos, sus trabajadores quedaron a merced de los empleos temporales, los outsourcing, que de inmediato reflejaron su vulnerabilidad ante la falta de derechos laborales, la pérdida de estabilidad y de poder adquisitivo.

Con el inicio del nuevo siglo, y ante las protestas sociales por los estragos causados, las empresas se ven en la imperiosa necesidad de ir más allá de las leyes y comprometerse de forma auténtica, comprobable y medible con la retribución de sus prácticas comerciales a la sociedad, la economía, sus clientes o grupos de interés (stakebolders) internos y externos, el cuidado del medio ambiente y el uso sustentable de los energéticos.

Palabras clave: marketing I.O, 2.0, 3.0 y 4.0, globalización, corporativismo, marcas, ética empresarial.

\footnotetext{
* Doctora en Ciencias Políticas y Sociales con orientación a comunicación por la Facultad de Ciencias Políticas y Sociales de la UNAM. Profesora de asignatura en la carrera de Ciencias de la Comunicación, áreas de Publicidad, Entretenimiento, y en la Maestría en Administración de Negocios de la UNAM, Universidad Anáhuac México y Universidad Tecnológica de México.
} 


\section{ABSTRACT}

The phenomenon of globalization, that had its moment of expansion and consolidation in the r990s, generated serious problems whose direct consequences were damage to the environment, abusive business practices, invasion of factories in poor countries where the workforce did not have a fixed place to live in, or rights, and were paid less than a dollar a day.

Factories owned by developed countries left suffered havoc, workers at the mercy of temporary jobs, outsourcing that immediately reflected their vulnerability given the lack of labor rights, the loss of stability and purchasing power.

With the beginning of the new century, and in the face of social protests over the ravages caused, companies are in urgent need of going beyond the laws and committing themselves in an authentic, verifiable and measurable way through their commercial practices, to take care of the environment, and use energy in a sustainable way to compensate society, its internal and external clients and stakeholders as this will also be economically beneficial for all.

Keywords: marketing I.0, 2.0,3.0y 4.0, globalization, corporate, brands, business ethics.

\section{INTRODUCCIÓN}

La discusión actual del replanteamiento de los tratados comerciales entre los países, en donde se debaten temas como el pago de aranceles por importaciones de productos maquilados fuera de sus fronteras (TLCAN, Capítulo I, Artículos ior al I05, Capítulo III, Sección B artículos 302-308), aunada a las condiciones laborales actuales, sacan a la luz la necesidad de reflexionar sobre el poder que cada nación tiene de decidir sus propias prácticas comerciales, como parte de su política interna.

Nos encontramos con la imperiosa tarea de legitimar el quehacer empresarial de los sectores de producción, transformación, comercio y servicios, que hoy más que nunca enfrentan una dura competencia en el mercado, con consumidores que exigen y demandan excelencia en la calidad de sus productos y servicios, compromisos con la sociedad y el medio ambiente, así como con las condiciones laborales que ofrecen en los países donde se establecen.

El presente artículo pretende explicar cómo los estragos de la globalización, las prácticas comerciales abusivas, la falta de sensibilidad social por el medio ambiente y los derechos humanos derivaron en el concepto de Empresa Socialmente Responsable y el compromiso que adquieren las empresas grandes, medianas y pequeñas al asumir esta nueva cultura labo- 
ral, que además queda expuesta en sus páginas web, redes sociales y negocios físicos en un espacio social-global donde empresarios, políticos y consumidores se juntan para discutir y dar seguimiento a las actividades que nos conciernen y afectan a todos (Klein, 2005, pp. 2I-22; Ortiz, 20IO; Cruz, Rositas y Mendoza, 20I3; Celaya y Herrera, 2007).

\section{PLANTEAMIENTO DEL PROBLEMA}

Con frecuencia los temas de la globalización, el corporativismo, las nuevas reglas políticas y económicas que enfrentan los mercados en comunidades y tratados de libre comercio suelen verse desvinculados de la evolución de las estrategias mercadológicas y publicitarias y más aún de los planteamientos éticos que los grandes corporativos se vieron obligados a adoptar, con la finalidad de aferrarse a ellos como una tabla de salvación que impidiese que se ahogaran en su propio desastre (Fortune, I991 y 1998; The Business Week, 1997, pp. 26-27; TLCAN, 2020).

Pero conscientes o no del compromiso que estaban adquiriendo, la mayoría de los corporativos primero y luego en cascada las grandes, medianas y pequeñas empresas tuvieron que pasar de la "apariencia” de ser ESR a ser Empresas Socialmente Responsables con todos los cambios de fondo en infraestructura, cultura y práctica comercial que esto conlleva (CEMEFI, 2020).

El presente trabajo pretende conjuntar estos elementos para analizar y descubrir los hechos, circunstancias y factores que lograron consolidar lo que hoy conocemos como Empresa Socialmente Responsable y lo que ello va a implicar en este contexto donde pareciera que se pretende regresar al proteccionismo comercial que vele por la seguridad laboral y económica de los países en un nuevo modelo de tratados comerciales que cambia las reglas del juego en las prácticas de negocios y posicionamiento de las marcas (TLCAN, 2020, segunda parte, Capítulo III, secciones A y B).

\section{OBJETIVOS}

Dar a conocer por qué emergieron tantas y tan variadas estrategias de marketing que fueron más allá de la relación de satisfacer las necesidades de un mercado a lograr un diálogo con el consumidor e integrarse en un estilo de vida que les genere satisfacción a ambos.

Reconocer el papel de la ética en las nuevas prácticas comerciales y analizar los prometedores beneficios de contar con la certificación de ser ESR. 


\section{HIPÓTESIS}

El aumento en la certificación de ESR compromete a la producción de bienes y servicios que satisfagan las demandas de diversos actores que rodean a la empresa como sus stakebolders internos (empleados) y externos (proveedores, consumidores y comunidad), grupos de activistas, ONG, autoridades reguladoras, socios comerciales nacionales e internacionales que pueden tener un efecto sobre su reputación y rendimiento de negocio. En consecuencia, el mantener relaciones sanas, transparentes y justas con las partes interesadas será un requisito esencial para mantener una ventaja competitiva en el nuevo orden económico que se está imponiendo en el mercado global.

Esta investigación no experimental, de tipo longitudinal, pretende demostrar las características con que debe contar una Empresa Socialmente Responsable en México. Según el Centro Mexicano para la Filantropía (CEMEFI, 2020), para obtener dicho distintivo y renovarlo cada año las empresas deben cumplir con:

I. Retribuir a la sociedad con sus operaciones económicas, sociales y ambientales de manera sustentable.

2. Contar con un código de ética y normas de conducta.

2.I. Contemplar el derecho humano al trabajo, la dignidad de las personas, derechos y libertades inherentes, trato amable igualitario y tolerante.

3. Medio ambiente: Realizar un consumo responsable y eficiente de papel, agua, y energías.

4. Prácticas comerciales: Fomentar prácticas comerciales justas y de calidad al brindar un mejor servicio a los proveedores y clientes.

5. Clima laboral: Ambiente laboral agradable que impulse las buenas relaciones basadas en el respeto, motivación y seguridad entre los colaboradores.

6. Anticorrupción y confidencialidad: Se rechazan y denuncia acciones impropias por parte de los socios, colaboradores y proveedores. Se preserva la confidencialidad y propiedad intelectual a través de una política de protección a la información que permita fomentar la legalidad dentro y fuera de la empresa.

7. Ética laboral: Ser congruentes con sus valores y acciones. Tener el derecho a formular quejas y denuncias, así como hacer sugerencias al código de ética y conducta

Según el CEMEFI (2020) y la Alianza por la Responsabilidad Social Empresarial en México (AliaR SE) las empresas privadas legalmente constituidas, clasificadas por su tamaño como 
Grandes de todos los sectores de la actividad económica, pueden participar en el proceso de diagnóstico para la obtención del distintivo ESR.

\section{OBJETIVO DEL DISTINTIVO ESR ®I}

Acreditar y reconocer a las empresas líderes por su compromiso de aportar valor social a su operación ante sus públicos de interés y que voluntaria y públicamente manifiestan:

- Su compromiso de implementación y mejora continua de una gestión socialmente responsable, como parte de su cultura y estrategia de negocio.

- Contar con políticas, estrategias y programas, que contemplen todos los ámbitos y niveles de actuación de la empresa.

- Orientar a la empresa hacia un modelo de gestión sostenible y socialmente responsable.

- Identificar oportunidades de mejora en la gestión integral de la empresa.

- Fortalecer la confianza de los grupos de interés en la empresa, que genere valor agregado a la imagen y competitividad institucional.

- Reconocer a las empresas líderes por su compromiso de aportar valor social a su operación.

Los segmentos comparados en este análisis son las io empresas mexicanas que figuran en el ranking de empresas Socialmente Responsables y las ıo marcas mexicanas más valiosas del país.

\section{ESTADO DEL ARTE}

\section{I.I. Concepto de mercadotecnia y su evolución}

Según Laura Fischer y Jorge Espejo, "el concepto de mercadotecnia social no es una simple definición, sino una forma de pensar o una filosofía de dirección que repercute no solo en las actividades de la mercadotecnia, sino en todos los elementos o departamentos integrantes de la empresa" (2004, p. I2). Pero ¿cómo fue que se inició este concepto? La mercadotecnia es una disciplina que se enfoca en el proceso de producción de un producto o servicio para el mercado. Dicho proceso implica entender las necesidades del mercado, conocer los hábitos 
de consumo de los clientes potenciales y saber qué esperan estos del producto o servicio. La mercadotecnia determina los lineamientos del concepto de marca y se encarga de atraer el mercado al que desea llegar.

Con el paso de los años, la publicidad, cuya actividad consiste en dar a conocer un producto o servicio al mercado con la misión de posicionar una marca, terminó por ser una estrategia de comunicación al servicio de la mercadotecnia.

Así, la mercadotecnia es la parte estratégica que localiza mercados potenciales, diseña productos que se ajustan a sus necesidades, idea el mejor empaquetado, presentación y etiquetado, hace investigaciones de mercado para asegurarse de la demanda que tendrá el producto, analiza a la competencia, fija los precios, elije los puntos de venta y marca los lineamientos que la publicidad deberá seguir para dar a conocer el nuevo producto.

Sin embargo, los cambios globales relacionados con el libre comercio, que surgieron a mediados de los años noventa y dieron como resultado las grandes consolidaciones corporativas, con nuevas prácticas comerciales caracterizadas por no respetar fronteras en ningún país, tuvieron como consecuencia inmediata comenzar a entender que la política interna de cada país ya no funcionaría igual (Klein, 2005, p. I82).

En ese tiempo, teóricos académicos, empresarios, economistas y políticos apenas podían imaginar el fenómeno denominado globalización.

Pronto comenzaron muchas movilizaciones alrededor del mundo, con fuertes consignas dirigidas a empresas como Nike, Monsanto, Shell, McDonalds, entre otros. Naomi Klein (2005) indaga qué factores crearon esta reacción negativa y qué liberó a una generación de gente joven a ser tan audaces y perseguir directamente a las multinacionales.

Esta idea aparentemente inocua, que había asaltado al mundo corporativo y que en ese momento no era percibido como un fenómeno político, sino tan solo como parloteo de los CEO, sólo era perceptible si se prestaba atención a las revistas de negocios o a los best sellers sobre cómo ganar un millón de dólares.

De acuerdo con Martorell (2010), la estrategia que iniciaron las marcas fue equiparar la marca con un determinado estilo de vida. Si las empresas pretendían ser exitosas y conquistar el mercado mundial, tenían que cambiar la mentalidad de ver a sus productos sólo como bienes de consumo, provenientes de su entorno y transformados en satisfactores de necesidades de los consumidores como, por ejemplo, tenis, películas, bebidas, computadoras, y pensar que el consumo de los mismos es un estilo de vida.

Esta idea de vender el concepto de "marca" o branding (Gómez, 20I4) en lugar de productos es muy reveladora, porque la publicidad saltó de los medios masivos de comunicación conocidos como ATL (Above the line) a tomar todo el escenario público como lienzo para exhibir publicidad, estrategia conocida como BTL (Below the line). 
La imagen corporativa era la explicación del por qué estábamos viendo más y más formas creativas de marketing dirigido a los jóvenes, era la explicación de por qué, a pesar de las promesas de más opciones, parecía que teníamos menos, debido a la consolidación corporativa.

También se hicieron escuchar cada vez más quejas sobre las fábricas o maquiladoras de bajo costo (trabajos temporales), y por qué la calidad del trabajo parecía disminuir en muchos lugares del mundo, no solamente en el mundo en desarrollo (Klein, 2005).

Asimismo, se explica por qué estas fuerzas que actúan en conjunto sin lugar, sin elección y sin empleos, convergieron juntas para crear las condiciones que coloquialmente Klein denomina como No Logo, frase que describe el espíritu de resistencia anticorporativa.

\section{I.2 Las nuevas marcas en el mundo. Marketing I.O}

En el nuevo mundo de marca (Gómez, 20I4), el proceso de utilizar un logo, en su forma más simple, es el proceso de marcar un producto de forma consistente con un logo (una imagen, una mascota, etcétera) algo que transmita el mensaje al consumidor, un mensaje de consistencia, de calidad. Este proceso se convirtió en algo realmente importante durante el advenimiento de la producción masiva, las mercancías eran productos salidos de las maquilas para transportarse al mercado.

De pronto, los productos que se compraban en las tiendas locales, en los establos, con los granjeros, con quienes el consumidor tenía una relación de vecindad, se arrancaron de raíz.

Con rapidez la mercadotecnia transitó de ser Marketing i.o al día de hoy, que es 4.0, (Kotler, 2013). La mercadotecnia tradicional o Marketing I.o, cuyo objetivo principal era el producto con el fin de que se vendiera y nada más; cedió paso al marketing 2.0, enfocado en el cliente. Este es el tipo de marketing que surge con la era corporativa, donde las marcas se enfocan en los gustos de los consumidores y que los clientes se sientan felices con el producto; el marketing 3.0, consecuencia de los movimientos y protestas anticorporativistas, se centra en los valores que el consumidor debe tener y se enfoca en ver al cliente como un ser humano con necesidades, inteligencia y emociones, se busca crear una imagen de marca que se preocupa por el medio ambiente y un mundo mejor. Finalmente, el enfoque de marketing 4.0 es predecir el comportamiento del consumidor, con estrategias basadas en la mercadotecnia digital, que permiten conocer el comportamiento del mercado en tiempo real. 


\section{I.2.I. Marketing, 2.0. Las marcas están en todos lados BTL}

Es a finales de los años 90 y principios de este siglo cuando comienza el bombardeo de las marcas con el Marketing 2.0. Se inician los anuncios BTL y las marcas invaden las famosas series de T.V. que ven los jóvenes, ante el desafío del zapping y la gran oferta de contenido televisivo. La famosa serie de Friends exhibe en la naturalidad de sus contenidos a Starbucks y Diet Coke; la serie Dawsons's Creek presenta su vestuario de Tommy Hilfger, con escenas donde se usan marcas como condones Trojan o tiendas como Kmart, y la serie Will \& Grace exhibe la marca Banana Republic.

Y también se invaden espacios naturales: Patrick Dory inventó una máquina para hacer anuncios impresos en la arena del mar, y algunas marcas se proyectaron con el fondo de la luna llena. Las marcas quisieron contar su historia, pero ¿̇ónde empiezan y dónde terminan sus límites?

A gran velocidad comenzaron a construirse en las principales ciudades plazas comerciales. Estas inundaron con su presencia todo tipo de colonias, reemplazando la plaza pública con plazas comerciales construidas con un diseño arquitectónico que simulaba la plaza pública, árboles, fuentes, bancas, locales comerciales con fachadas de casas, kioskos; el problema es que estos lugares no permiten el activismo político o social.

La idea de censura corporativa empieza a escalar, a ser más sofisticada para obligar al silencio; por ejemplo, Walmart es un corporativo muy grande que, entre otras cosas, controla gran parte de la música y de los libros, lo que le crea problemas con su imagen de marca, que a menudo entra en conflictos con la expresión artística.

Doug McMillon (CEO Walmart) señala: "Queremos que nuestras tiendas vendan productos que cualquier familia estaría orgullosa de poseer en su hogar” (Klein, 20I2, 2I: 4I).

Walmart, que con frecuencia aparece en la cima de las compañías del Fortune 500 y como la empresa que emplea a más personas en los Estados Unidos, es también una marca poderosa cuya identidad corporativa es familiar; en México, grupo Armonía edita su revista Siempre en familia y muy al estilo de Disney, sobre todo en la manera de generar su identidad, están orgullosos de haber creado una tienda para toda la familia.

Esto, como veremos ejemplificado más adelante, cuando abordemos el tema de Empresa Socialmente Responsable, no tiene nada que ver con los valores de la compañía, es tan sólo una estrategia de marketing 2.0, con la cual, al identificarse como tienda de carácter familiar, son capaces de atraer a todos los miembros de la familia con los productos que exhiben en sus anaqueles.

Esta estrategia de ser una tienda de carácter familiar obviamente ha contribuido a su increíble rentabilidad, pero también se ha visto en el dilema ético de chocar una y otra vez con la expresión artística. 
Tienen problemas con las letras de las canciones de rap, reggaetón, ritmo de blues, soul y funk contenidos en $\mathrm{CD}$ o el arte presentado en las portadas de alguna revista, que no son apropiadas para la imagen que Walmart quiere proyectar.

Es lógico pensar que, al tratarse de una firma privada, tienen todo el derecho de decidir lo que ponen en sus anaqueles, incluyendo productos del laboratorio Genomma Lab, cuyos "productos milagro" tuvieron que ser retirados de sus pisos de venta (2015). Sin embargo, es la escala en la que esto ocurre lo que marca la diferencia, pues lo que esto significa para la compañía discográfica, la editorial o el laboratorio, es que acaban de perder un $30 \%$ de sus ventas, y esto no lo van a aceptar. Así que rehacen el CD y también internalizan la ética y los valores morales de Walmart cuando escogen a nuevos artistas y cuando piensan qué tipo de cultura van a promocionar en primer lugar. "El medio es el mensaje", como decía McLuhan.

Existe un tipo de censura preventiva de la cual nunca oímos hablar, o raramente nos enteramos de algo, a menos que lo retiren de la venta al público, pero lo que nunca sabemos es de la censura detrás del telón, del control preventivo y las "sugerencias" que ocurren en esta censura silenciosa.

\section{I.2.2. Marketing 3.o. Expansión y consolidación corporativa}

La mayoría de las marcas no son nuevas, algunas ya llevan siglo y medio en el mercado y siguen siendo líderes en su ramo, pero en su objetivo primario -la producción de medios de consumo que van a marcar con su identidad corporativa- ahora se ven en la necesidad de producir una imagen de marca más sólida, cuyo contenido corporativo pueda ser utilizado en diversos medios, y la fabricación de productos de consumo pasa a un segundo plano como algo casi accidental.

El paradigma corporativo más famoso que expone Klein (2005) es el caso de Nike, y lo explica así: cuando se compran unos tenis Nike, aunque vemos el logo emblemático de la palomita y su tipografía en el calzado, la famosa empresa no ha fabricado ese producto.

Nike compró ese producto, y la forma como ocurrió es probablemente que contrataron a un agente comercial en Hong Kong, el cual les dijo que podría fabricar su calzado a un costo más bajo, pero este agente a su vez contrató para producir ese calzado a una fábrica en China, Vietnam o Indonesia, porque se busca fabricar el calzado a un costo todavía más bajo, y así encargaron a otra compañía la producción. Con cada paso, la cantidad de dinero que reciben los trabajadores disminuye, y así acabamos con un laberinto de maquilas con contratos y subcontratos. 
El paradigma de Nike, como se lo denomina, fue mostrando el futuro de un mundo corporativo. La única forma posible de que un producto sea barato, o más barato que otros, no es ahorrando en materiales, porque la marca avala cierto nivel de calidad adecuado a su nombre y prestigio; no existe otra fuente para abaratar el precio que el reducir los salarios de los trabajadores.

En las noticias acusan a Nike: "Grupos de defensa de los derechos humanos dicen que Nike paga a trabajadores en Asia menos de i dólar al día... y que emplean a niños en algunas de sus plantas de producción" (Calvo, 1996).

Una manera de mantener los salarios bajos es controlar a la fuerza laboral, asegurándose de que no se organicen en sindicatos o uniones para exigir cosas como seguridad social y seguridad laboral.

Estos productos de consumo, llámense calzado, electrodomésticos, ropa, computadoras, celulares, etcétera, son realizados en las llamadas "zonas de proceso de exportación", mejor conocidas como maquiladoras, cuya principal fuerza laboral son mujeres en un $80 \%$ con edades aproximadas de I8 a 25 años.

Entre los países pobres, subdesarrollados y sin oportunidades de empleo, existe una especie de subasta global por prometer los mejores precios, condiciones fiscales, económicas y sociales, y esa es la razón por la cual, aun cuando la promesa de la globalización es llevar desarrollo a los países más pobres, hacer que los salarios suban y lograr que su situación mejore, lo que de verdad ocurre es que somos espectadores de una carrera que va hacia el fondo, en la cual unos países tratan de pujar más alto que otros, y lo único que consiguen es que se

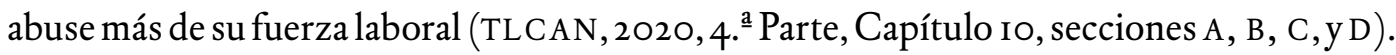

Pero el significado para una compañía como Nike es que el producir este tipo de mundos utópicos de marca cuesta mucho más caro que solamente promocionar el producto. Así, muchas compañías han declarado abiertamente: "Hemos tomado una decisión, hemos decidido construir nuestra propia marca”. Pero esa decisión acarrea consecuencias, y una de ellas es que, una vez tomada, a menudo es acompañada por la decisión de vender sus maquiladoras y utilizar el modelo de Nike, una compañía que posee toda la propiedad intelectual que se pueda imaginar, pero que no posee una sola fábrica o maquiladora (TLCAN, 2020, 6. Parte, Capítulo XVII).

Cuando una compañía decide implementar un modelo de esta naturaleza, obviamente afecta inmediatamente a la fuerza laboral, y ese fue el caso en Estados Unidos y Europa, donde se eliminaron empleos al cerrar las maquilas e irse al extranjero, principalmente a México, China, Vietnam, y Taiwán.

Esos empleos en Estados Unidos se sustituyeron con ofertas de trabajo temporal; los dos proveedores de empleo más grandes fueron Walmart y Manpower, esta última una 
firma muy grande que no produce nada, tan sólo proveen gente a las vacantes temporales de empleo. Según el listado de CEMEFI (2020), Manpower celebra por i8 años consecutivos el distintivo de ser ESR y Walmart Centroamérica, 20 años, pero ninguna de las dos es mexicana, sólo tienen presencia en nuestro país.

\section{I.2.2.I. Inicia el activismo anti corporativo con marchas y protestas}

Klein (2005) explica cómo las marcas nos relacionan con la globalización, pues cuando se elige un calzado, celular, computadora, electrodoméstico, etcétera, tenemos en las manos la historia completa de la globalización.

Un pantalón de mezclilla, por ejemplo, la mezclilla se produce en México, se envía a Taiwán a una fábrica operada por algún contratista coreano que un agente comercial de Hong Kong contactó, y este último es quien negocia directamente con una compañía en San Francisco California.

Al observar estos hechos, afirma Klein (2005), es posible analizar el rastro de todos los elementos a través de la economía global, y no sólo eso, sino también averiguar cuánto dinero esa misma compañía que trata de vender sus jeans le paga a una "superestrella" para crear un estilo de vida con el uso del producto, y así se podrá apreciar la disparidad de la economía global, los ganadores y los perdedores.

Lo que se ha observado en los últimos años es una explosión de "activismo investigativo" que se especializa en las grandes marcas, tiene partidarios que han "removido la marca" tratando de mirar tras ella, eliminando la fachada y averiguando cómo son producidas sus mercancías. Existen grupos laborales en Estados Unidos que han facilitado visitas a trabajadores de Nike, Gap, entre otros, para que asistan a los campus universitarios o a centros sociales comunitarios para informar a la gente cómo son producidos esos artículos.

Y, por supuesto, esto es algo molesto para esas compañías que, aun siendo motores principales de la globalización, no creen en ella, o al menos no en este tipo de globalización activista que pone al descubierto sus actividades y las cuestiona.

El sistema de los grandes corporativos globales depende por completo de que el mundo de la producción y el mundo del consumo se encuentren seguros y que permanezcan sin tener ninguna conexión directa en sus raíces, porque así podemos conocer sus secretos detrás del perfecto estilo de vida que proyectan las marcas.

En la actualidad, estas marcas se han convertido, de muchas maneras, en los objetos más visibles de la globalización, tanto que cuando presenciamos una protesta o durante ella, encontramos grandes concentrados de policías antimotines protegiendo establecimientos 
como Starbucks, McDonald's, Walmart, y esto llama la atención como algo tremendamente simbólico, que encontremos a la fuerzas represivas del Estado protegiendo las fachadas de lo que se considera la puerta de entrada al mundo de la globalización.

Y lo que este activismo está consiguiendo es reunir a más y más activistas socio-conscientes afuera de las grandes plazas comerciales y de las tiendas gritando "Sabemos cómo producen sus mercancías" (Calvo, 1996).

Eso es lo que las compañías consiguen. Convierten a la globalización en algo real, cuando se advierte la conexión entre la comida empaquetada que comes, la ropa que llevas puesta y los juguetes que compras para tus hijos.

El resultado de todo este activismo contra las marcas, que Klein (2005) documenta detalladamente, es que las grandes marcas deciden tomar el control de su crisis de imagen, que comenzaba a afectar sus ventas y, por ende, su economía, pues cayeron en la cuenta de que pagaban más dinero porque no se dijeran cosas negativas de ellas, como que contaminaban el medio ambiente, desechaban tóxicos en los ríos, el mar, el aire, estaban acabando con algunas especies animales, tala descontrolada de árboles, etcétera, que en publicitar sus firmas y posicionar una buena reputación de su marca.

Las estrategias de comunicación de mercadotecnia que salieron en ayuda de la difusión de su imagen se conocieron como green marketing, y eran una serie de acciones mercadológicas que incluían retirar de la producción componentes tóxicos que ocasionaban daños en la salud de las personas (desde malformaciones hasta enfermedades cancerígenas y la muerte). También se invertían fuertes cantidades de dinero en hacer publicidad que difundiera tanto las acciones de cambios en los componentes contaminantes como de resarcimiento del daño.

Un ejemplo de ello fue el caso de Dupont (2017), cuando salió a la luz que la planta de Washington Works de DuPont, al sur de Parkersburg, Virginia Occidental, usó el producto químico tóxico C8 durante más de 50 años. El mes de abril, la EPA bajó su "nivel de acción" para C8 en agua potable a 0.07 partes por billón. En ese nivel, DuPont debe proporcionar agua potable a los residentes cercanos.

A lo largo de 75 millas del río Ohio -de Parkersburg, Virginia Occidental, a Pomeroy, Ohio- el agua de los pozos contaminados con C8 se filtra a través de carbón activado granulado antes de llegar a los grifos en los hogares y las empresas. El producto químico se ha atado a una serie de cánceres y trastornos de salud.

El estudio de 70 millones de dólares, financiado por un acuerdo de DuPont en 2005, fue el fundamento de la investigación de un panel científico que concluyó que existía un "vínculo probable” entre C8 y seis enfermedades: cáncer de riñón, cáncer testicular, colitis ulcerosa, enfermedad tiroidea, hipertensión y colesterol alto (Vizcay, 20I7). 
Las grandes marcas iniciaron un movimiento de activismo social, donde demostraban que no eran insensibles a los daños ocasionados a la sociedad y al medio ambiente, pagaron por publirreportajes que exhibieran detalladamente en los medios masivos de comunicación cómo emprendían acciones en el rescate animal, como el anuncio "Salvo los salva-Pelícanos" (2008).

Pronto campañas publicitarias como "Dove lucha contra el cáncer de mama”; Bonafont se une en alianza con ONU Mujeres, a favor de la igualdad de oportunidades laborales entre hombres y mujeres; Grupo Danone se une a la lucha contra el cáncer de niños; Tequila Cuervo lanza su campaña "Conductor designado" para concientizar al público sobre no conducir bajo los efectos del alcohol.

Con estas acciones, la mercadotecnia 3.0 crea la estrategia de comunicación conocida como marketing social, con el objetivo es darle un carácter humano y social a las marcas que pretenden ser embajadoras de la prevención y patrocinadoras de las víctimas de sus operaciones de producción que tanto daño causaron a la salud humana, animal y al medio ambiente, sin pasar por alto, por supuesto, las condiciones laborales de sus empleados y empleadas.

\section{MARCO TEÓRICO Y CONTEXTUAL}

\section{I.2.3. Marketing social}

¿Qué es la mercadotecnia social o social marketing? Según Alan Andreasen (2010), "la mercadotecnia social es la aplicación de las técnicas de la mercadotecnia para el análisis, planteamiento, ejecución y evaluación de programas diseñados para promover la aceptación, modificación, rechazo o abandono del comportamiento voluntario de las personas a fin de ayudarles a mejorar su propio bienestar y el de su sociedad".

Según Philip Kotler y Zaltman (197I) el marketingsocial tiene sus orígenes en I97I, cuando se emplean las estrategias de la mercadotecnia comercial para promover causas sociales.

En la década de los setenta, los pocos autores que manejaban el concepto de mercadotecnia social, como Namakforoosh y Kotler, creían firmemente que la mercadotecnia comercial se podía emplear tal cual en promover causas sociales de la misma forma que se posicionan productos en el mercado. Rápidamente varios estudiosos del tema señalaron que se pasaría de las 4 P de la mercadotecnia a las 7 P. Las cuatro clásicas son: Producto, Precio, Plaza y Promoción, y añaden 3 P más: People, Process y Physical Evidence, siendo esta última la que va dejando (regalos) que sirvan para recordar la marca y asociarla con alguna causa.

Pero no podían estar más equivocados. Cuando estos autores señalaban este poder de las estrategias de mercadotecnia para beneficio social se referían a campañas educativas, 
informativas o sensibilizadoras en las que de inmediato se hizo notar que no cabían todas las organizaciones.

Una empresa comercial defiende siempre su política, cultura, valores e ideología comerciales, donde no siempre las causas sociales coinciden, provocando — como lo vimos en el caso de Walmart-que problemáticas como el feminismo, aborto, racismo, discriminación, género, y actualmente la campaña de etiquetados claros que promueve la Secretaría de Salud en México, por mencionar algunas, no coincidan con sus "bellos mundos aspiracionales de marca”.

Así, tenemos que las marcas sí quieren comunicar que tienen un legítimo sentido de empatía y que les importan las causas sociales; sin embargo, ninguna quiere ver comprometida su identidad corporativa plasmada en su logo asociada con un niño verdaderamente enfermo de cáncer, sida, desnutrición, etcétera. De manera que, como se trata de una estrategia de "simulación de aparente empatía", su interés es sólo comunicar el aspecto emocional de "la valentía", "la lucha por querer sanar", o la preocupación por los demás con la imagen de marca que transmite un mensaje positivo de superación de la adversidad y preocupación por causas sociales o ambientales.

Los beneficios de ser altruistas son muchos, pero sobre todo les aseguran una gran reputación y excelente imagen de preocupación social ante los ojos de sus consumidores.

Es por ello que muchos autores, como quien escribe este artículo, encontramos que hacer publicidad social y hacer mercadotecnia social son dos acciones diferentes en cuanto objetivos, intención y actividades.

\section{I.2.3.I. La publicidad social tiene por objetivo tocar corazones mediante la producción emocional que genera la voluntad de moverse en beneficio de otros, y para lograr dicho objetivo no le importa sacar el lado más crudo y desgarrador del problema.}

Además, la publicidad social, puesto que no pretende anunciar ningún producto, sino lograr los objetivos de concientizar, sensibilizar e informar sobre temas en materia de salud, medio ambiente, valores, educación, cultura, arte o deporte, no entra en conflicto con políticas y valores de ninguna empresa, es más libre en cuanto a su expresión creativa. Por ello, quienes hacen publicidad social son las asociaciones civiles, las ONG, o los gobiernos, cuyos fines no son lucrativos.

Pero lo que es de fundamental importancia es que asociaciones civiles como APAC, AMANC, Fundación John Langdon Dawn, Fundación Michou y Mau; ONG como Cruz Roja, Amnistía Internacional, WWF, Save the Children; secretarías de Estado y órganos de gobierno, como las secretarías de Salud y de Educación, Administración Tributaria, 
Finanzas, CONAGUA, etcétera, se forjen una reputación que les dé difusión a sus actividades, credibilidad, la confianza de que apoyarlas es apoyar una causa legítima que nunca hará quedar mal o a comprometer la integridad de ninguna empresa o gobierno que los apoye.

Es importante considerar que cada una de las instituciones antes mencionadas tiene sus valores, identidad corporativa, cultura, que deben quedar reflejadas en sus mensajes, como demostración de su carácter moral, pero no como limitante creativa.

Sin embargo, la estrategia conocida como marketing social cuida mucho las formas políticamente correctas de exhibir la marca y las causas que defiende, usando esa censura silenciosa que le permite seleccionar causas sociales con las que se pretende identificar, la forma como se va a producir el mensaje cuidando siempre que la marca se vea bien, y que el apoyo a la causa le genere jugosas ganancias económicas, y la aceptación de su público objetivo.

\section{MARCO METODOLÓGICO}

De acuerdo con el análisis longitudinal que se hizo de 2014 a 2020, tenemos que las marcas más valiosas en el 20I4, según El Financiero, fueron Corona, Telcel, Televisa, Bodega Aurrerá, Modelo, Liverpool, Bimbo, Cemex, Banorte y Telmex (Gráfica I).

\section{GRÁFICA 1. LAS 10 MARCAS MÁS VALIOSAS DE MÉXICO, 2014}

De acuerdo con el ranking de Marcas Más Valiosas de México de Brandz y Kantar, Corona ocupa el primer lugar. La marca de cerveza tiene un valor de 7 mil 647 millones de dólares.

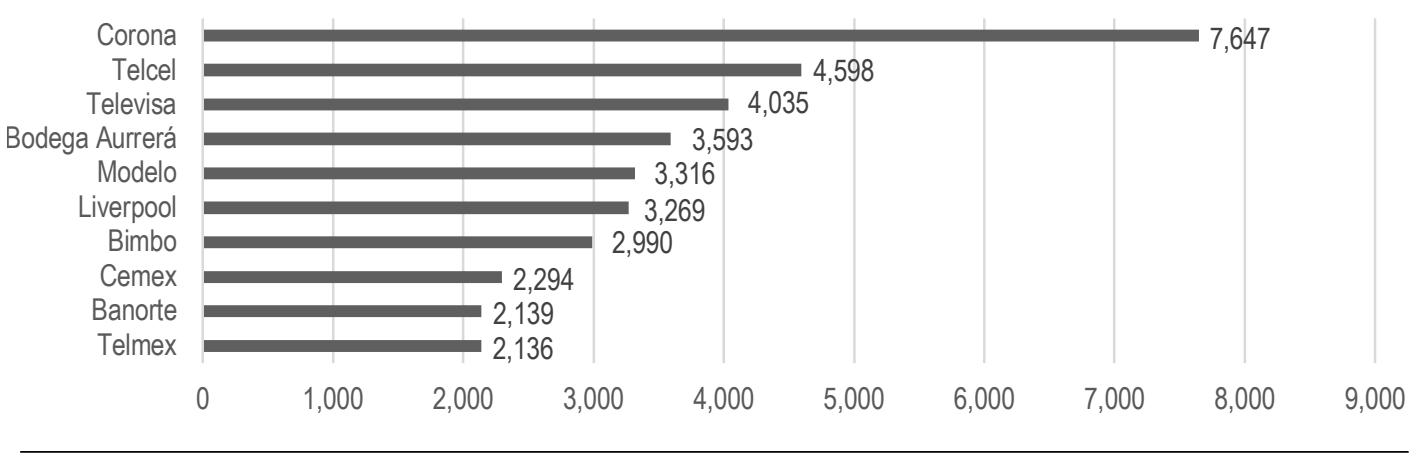

FUENTE: El Financiero, 15 de julio de 2014. 
Y en el 2020, según el ranking de empresas más valiosas, tenemos las siguientes marcas: Corona, Pemex, Claro, Victoria, Modelo, Telcel, Cemex, Bodega Aurrerá, Bimbo, Oxxo (Gráfica 2).

GRÁFICA 2. LAS 10 MARCAS MÁS VALIOSAS DE MÉXICO, 2020

Nota: El valor de la marca se muestra en millones de dólares

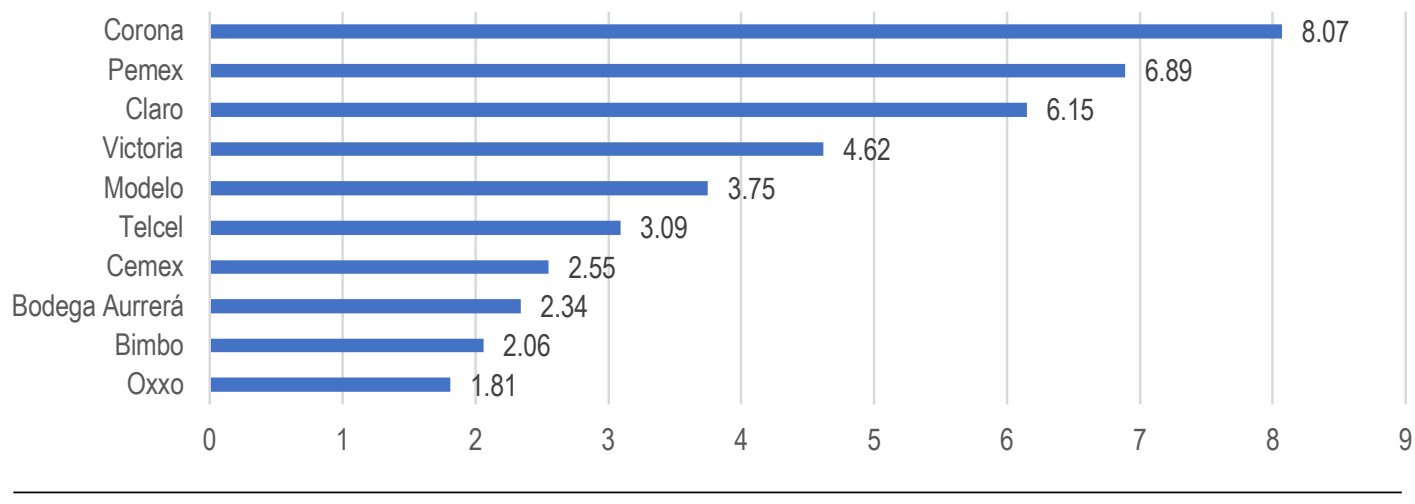

FUENTE: Burgueño, S., 2020.

GRÁFICA 3. VALOR DE MARCA EN ESR

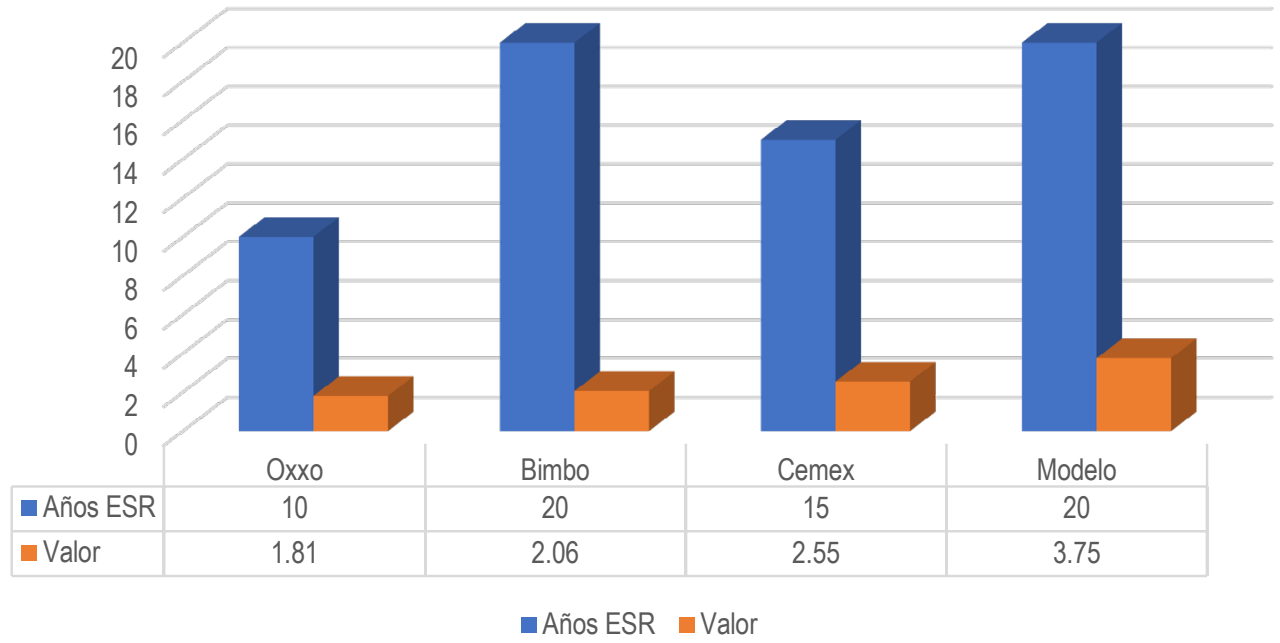

FUENTE: elaboración propia. 
Si comparamos el listado de 2014 con el de 2020 , encontramos empresas mexicanas que se han mantenido en el listado de las marcas más valiosas en dólares, liderando Corona, de grupo Modelo, Bimbo y Cemex. En el ranking de 20I4 Oxxo estaba en el lugar número I2 con II ooo tiendas en la república, 3 aperturas diarias, productos de marca propia, y un valor de 2615 millones de dólares. Y Bodega Aurrera, en el 20I4, estaba en $4^{\circ}$ lugar, con su campaña Mamá Lucha y ıoı6 millones de dólares.

En congruencia con su valor de marca y la forma como la han mantenido, encontramos que según el listado de CEMEFI 2020, algunas de estas marcas han renovado su distintivo de ser ESR: Grupo Bimbo y Grupo Modelo por 20 años consecutivos, y CEMEX I7 años consecutivos, y Oxxo por I3 años.

En el caso de Bimbo, esta marca ha encabezado campañas como "Comprometidos con la Salud”, iniciativa que se llevó a cabo en I 7 países en donde la marca tiene presencia, para contribuir a la concientización de estilos de vida saludable entre la población. Esta idea ha sido parte de su mercadotecnia social, según consta en su página Web. Las medidas anunciadas atienden las recomendaciones aprobadas por la $63^{\circ}$ Asamblea General de la Organización Mundial de la Salud y su campaña está sujeta al Código de Autorregulación Publicitaria de Alimentos y Bebidas dirigidas al público infantil (PABI). Ha participado con productos como Tía Rosa en la lucha contra el cáncer de mama (AMLCC).

En 20I9, en la edición de Effies México en la que reconocen a los mejores trabajos de las industrias de marketing y publicidad, Grupo Modelo se llevó varios galardones en la publicidad de sus marcas Victoria, Corona y Bud light por sus campañas "Chingones hasta la muerte", "La suerte no juega” y "Desfronterízate”, y en categoría social con \#Dejaelcoche.

Entre otras campañas de publicidad social podemos citar la de CEMEX 2005 "Señales", que expone los beneficios del concreto en comparación con el asfalto para disminuir accidentes, y la de Bodega Aurrera, campaña de ahorro "Morralla".

\section{MARKETING 4.O RESPONSABILIDAD SOCIAL EMPRESARIAL}

\section{I Marketing social: Sus retos y desafíos con la llegada de las redes sociales}

La mercadotecnia social, que se originó con la idea de legitimar a las marcas en su conciencia social-ambiental y resarcir su imagen comercial, derivaría en una estrategia que debía dar el paso obligado de la "simulación" por el interés y la empatía social a la "acción visible, al escrutinio público”. 
Las prácticas comerciales actuales, además de estar globalizadas, ahora están conectadas por las redes sociales, por lo que las marcas son seguidas en todos sus pasos por el "gran ojo" que todo ve, todo escucha y todo lo difunde de manera veloz.

En este nuevo contexto, la responsabilidad social empresarial (RSE) obliga a las empresas a tener un compromiso legítimo y evidenciado con la sociedad. Esta nueva forma de hacer negocios, en la que no solo importa lo que se gana, sino cómo se gana, compromete a las empresas a dar testimonio claro y medible de cómo logran ser económicamente sustentables, obtener utilidades duraderas, proveer buenas condiciones laborales a su capital humano, considerar a sus vecinos (entorno social) como comunidad, y establecer relaciones sanas y duraderas con sus stakebolders (interesados) externos.

Las nuevas empresas y los corporativos que quieren alcanzar la imagen de Responsables Socialmente con sus grupos de interés, internos y externos, y con los mercados, deben ir más allá del cumplimiento de las leyes, deben asumir un compromiso cívico de la empresa, tener un carácter voluntario, ética empresarial, respeto por la dignidad humana y lograr un equilibrio económico, medioambiental y social.

El Centro Mexicano para la Filantropía (CEMEFI, 2008, p. 8) agrupa las acciones responsables en seis dimensiones: I) económica interna, la cual implica la responsabilidad con los accionistas; 2) económica externa, relacionada con la aportación impositiva correspondiente y generación de bienes y servicios útiles para la comunidad; 3 ) social interna, relacionada con la calidad de vida en el trabajo ; 4) sociocultural y política externa, enfocada a la generación de condiciones que fomenten el espíritu empresarial; 5) ecológica interna, orientada a evitar daños ambientales por sus procesos y productos; y 6), ecológica externa, encaminada a preservar la herencia ecológica. Uniapac Latinoamericana (2008, p. I8) sólo considera tres dimensiones: ética y transparencia, calidad de vida, y generación y distribución de la riqueza. Finalmente, la propuesta del organismo Acción Empresarial (200I) plantea tres dimensiones principales: social, económica y medioambiental, dentro de las cuales definen cinco líneas estratégicas: ética empresarial, calidad de vida laboral, medioambiente, compromiso con la comunidad y mercadotecnia responsable. La ética empresarial hace referencia al desarrollo, difusión y práctica de principios éticos con clientes proveedores, trabajadores y gobierno (Acción Empresarial, 20I2, p. 4).

El desarrollo de una estrategia de Responsabilidad Social Empresarial (R SE) es en sí mismo un negocio bastante rentable, porque asegura procesos de negocios de calidad, transparentes, medibles y susceptibles de ser mejorados constantemente. Se logra establecer relaciones con clientes internos y externos de mucho mejor calidad por sus acreditaciones y calificaciones, disminuyendo así la rotación de personal y malas experiencias o inversiones, al mismo tiempo que se vuelven empresas inspiracionales con un gran sentido de pertenencia por 
parte de sus colaboradores; respeto, seguridad y credibilidad por parte de sus proveedores y comunidades a las que pertenecen y donde logran mejoras, así como más transparencia en sus relaciones con los gobiernos.

Todas las acciones que las empresas llevan a cabo para ser acreditadas como RSE se exhiben públicamente en sus sitios Web, redes sociales y foros empresariales, donde la sociedad acredita o desmiente lo que hacen.

\section{ANÁLISIS Y DISCUSIÓN DE RESULTADOS}

\subsection{Responsabilidad social empresarial y los grupos de interés}

Las organizaciones se ven cada vez más comprometidas a tener y exhibir un comportamiento responsable, no solo en su actividad económica y empresarial, sino también en el modo de asumir sus responsabilidades con todos los stakebolders con los cuales se encuentran vinculadas. Las organizaciones están en proceso o comienzan a vislumbrar la posibilidad de formar parte de "la dimensión ética de la cultura empresarial" la cual, entre otros aspectos, consiste en el reconocimiento y el respeto de los valores éticos implícitos en su actividad.

Las organizaciones, como las personas, poseen un êthos (carácter) que les es propio y las identifica, y que las hace más o menos responsables, más o menos confiables y más o menos éticas. Como organización, la empresa posee una estructura definida que le permite adoptar decisiones colectivas que no pueden ser atribuidas a un individuo o grupo de individuos, sino que comprometen a la estructura empresarial como un conjunto. Por ello, debe tomar conciencia sobre qué valores y metas deben orientar sus decisiones; pero a su vez, como sujeto moral, debe asumir la responsabilidad de sus decisiones y las consecuencias que de ellas se derivan.

En México, el Centro Mexicano de Filantropía (CEMEFI) y Aliarse otorgan el distintivo de ESR a las empresas que demuestran asumir el compromiso de mantener vigente la cultura de la responsabilidad social durante todo el tiempo de vida de la empresa. Es por ello que este distintivo se renueva cada año, y la grata sorpresa es que hay empresas que ya llevan 20 años con la consolidación de este distintivo y cada año se suman muchas, muchas más. Para este año cerca de 500 empresas alcanzaron el nivel para recibir el distintivo.

Las io empresas que figuran en la lista de manera consistente son: I) Grupo FEMSA, 2) CEMEX, 3) Coca-Cola, 4) Cuauhtémoc Moctezuma, 5) Grupo Modelo, 6) Banamex, 7) Grupo Bimbo, 8) Herdez, 9) Walmart y Io) Telmex. 
El problema con las últimas dos empresas es que recientemente se han visto envueltas en escándalos, por adeudo de impuestos o mal trato al personal (terremoto 2017), que ponen en entredicho su compromiso moral con la sociedad, manteniendo en los mercados la percepción de simulación y no de compromiso con la cultura SR (La Jornada, 2020; El Universal, 2020).

Las empresas que ingresan a la cultura de ser ESR deben considerar como parte de su identidad corporativa y práctica diaria la retribución que deben dar a la sociedad con sus prácticas económicas, sociales y ambientales de manera sustentable; contar con un código de ética y conducta propio que fomente el desarrollo humano y profesional, velar por los derechos humanos, lo que conlleva respetar sin excepción alguna la dignidad de las personas, derechos y libertades inherentes, trato amable, igualitario y tolerante.

También deben comprometerse a realizar un consumo responsable y eficiente de papel, agua y energía; prácticas comerciales justas y de calidad al brindar un mejor servicio a los proveedores y clientes; un ambiente laboral agradable que impulse las buenas relaciones basadas en respeto, motivación y seguridad entre colaboradores.

Están obligadas a rechazar y denunciar acciones impropias por parte de sus socios, colaboradores y proveedores; preservar la confidencialidad y propiedad intelectual a través de políticas claras de protección a la información para fomentar la legalidad dentro y fuera de la empresa; la ética laboral debe seguir las acciones de la empresa, fomentar el respeto a los valores de la empresa, ejercerlos y enriquecerlos; finalmente, dar el derecho a los empleados a presentar quejas, denunciar y hacer sugerencias al código de ética y de conducta.

\section{RESULTADOS}

Del Prado (20I8) señala que el liderazgo profesional con sentido ético no es una calidad exclusiva del jefe o autoridad, es la cualidad mediante la cual se realiza la persona junto con los otros, a partir de la cooperación, en la construcción del buen vivir.

Esto quiere decir, si lo trasladamos al liderazgo profesional de las empresas, que no se logra más que en colaboración con todas las empresas y grupos de interés con los que mantiene relaciones comerciales, porque ya no es posible vivir en un mundo de simulación, de aparentar que tienen empatía con los demás, porque la mercadotecnia social en todo momento dará fe, testimonio y pondrá en evidencia su actuación cada vez que una empresa pretenda acreditar su reputación.

Con la llegada del mundo digital y los consumidores entendidos como audiencia activa, participativa y generadora de opiniones, el Grupo BPMO recomienda tener en cuenta: 


\section{Perfil de su público objetivo: ¿a qué tipo de comunidad se dirige?}

Al convertirse Internet en el canal preferente de comunicación e información de los jóvenes, es más fácil generar una conversación en la Red entre este público que entre personas adultas. Si su producto se dirige a personas de entre I 8 y 35 años, los nuevos medios digitales deberían ser uno de los ejes clave de su estrategia de comunicación.

Por otro lado, si su producto se dirige a un público especializado, como científicos, programadores o médicos, la Red le ofrece muchas oportunidades para escuchar qué dicen sobre su producto y crear una conversación directamente con ellos.

\section{La capacidad de interconexión de sus clientes}

Cuanto más conectados estén sus clientes entre sí, más dependerá de las nuevas tecnologías para posicionar correctamente su producto o servicio en el mercado.

Varias empresas han decidido fomentar la interconexión de sus clientes con el fin de crear una comunidad más compacta. En los últimos meses, medios de comunicación como El País, La Vanguardia, El Correo y El Mundo, los diarios gratuitos Qué! y 20 Minutos, y el canal de televisión Telecinco están llevando a cabo iniciativas para crear grandes comunidades de clientes que participen en la redacción de las noticias. El objetivo es fidelizar a los clientes facilitando nuevas formas de relación entre los lectores y el medio.

\section{El enfoque de sus estrategias de marketing y comunicación}

Por último, los expertos en marketing digital recomiendan analizar si su propia estrategia de comunicación genera conversación entre potenciales clientes. Algunas marcas, como Audi, Línea Directa o BMW, lanzan campañas de publicidad que tienen como objetivo provocar una conversación sobre las mismas en la sociedad. ¿Provoca su estrategia una conversación? (Celaya, 2007: 80-8I)

De esta manera, la empresa escapa de los límites del espacio privado para constituirse en una institución comercial-social sobre la cual convergen diferentes intereses. Y su ética será la que oriente y armonice estos intereses y relaciones sociales y comerciales que surjan en el desempeño empresarial. 


\section{CONCLUSIONES}

Las estrategias de mercadotecnia que hemos visto emerger en estos últimos veinte años han tenido su razón de ser en la necesidad de las empresas de hacer notar sus marcas y el compromiso que estas tienen con el desarrollo económico y social de los países donde se establecen, así como el compromiso de mantenerse de manera sustentable con el medio ambiente y de brindar desarrollo profesional a sus trabajadores.

A partir del marketingsocial se han desarrollado estrategias mercadológicas complementarias que han contribuido a que las marcas fijen, desde la planeación de mercadotecnia, las bases y requisitos del desarrollo de sus productos y servicios mediante políticas internas que respondan a la necesidad de apegarse a los valores, misión y visión de la empresa, los cuales deben ostentarse en todo el proceso, desde la orientación al trabajo en equipos multidisciplinarios y multiculturales hasta resultados que cumplan con las expectativas sustentables que las certifican y acreditan con RSE.

Dichas variantes de la mercadotecnia revelan que las marcas están muy atentas a cómo y en alianza con quién llevan a cabo la mezcla de estrategias complementarias a la mercadotecnia y la mercadotecnia social, como son marketing de interrupción, marketing de recomendación, fidelización, patrocinios, contenidos (content marketing), marketing a través de influencers, acciones de growtb backing, product placement, street marketing, mercbandising, endomarketing, neuromarketing.

Ninguna de estas estrategias se aplica de manera independiente, todas son complementarias y lo que hacen es comunicar los valores de la marca al dar satisfacción a los consumidores, acercarse a ellos, provocar el diálogo, su participación y lograr que sus productos sean parte de un estilo de vida que ellos se sientan orgullosos de ejercer, porque con su testimonio en redes sociales dan fe de la reputación de la marca, pero también serán sus primeros críticos de manera exponencial.

\section{REFERENCIAS}

Acción Empresarial (20I2).¿Qué es la RSE? Recuperado de: https://www.comunicarseweb.com/sites/default/files/biblioteca/pdf//1305685296_RSE-Gobernanza-medicion-y-control-de-gestion.pdf

Andreasen, A. (1995). Marketing social change: changing bebavior to promote bealth, social development and the environment. Jossey-Bass.

Burgueño, S. E. (2020, 28 de abril). México, las marcas más valiosas 2020. https://es.statista.com/ estadisticas/1024213/ranking-de-las-marcas-mexicanas-mas-valiosas/ 
Celaya, J., y Herrera, P. (2007). Comunicación empresarial 2.0. La función de las nuevas tecnologías sociales en la estrategia de comunicación empresarial. GRUPO BPMO ediciones.

CEMEFI (2008). Centro Mexicano para la Filantropia. http://www.cemefi.org/spanish/content/ view/1760/25/

CEMEFI (20I8). Guía para la administración de una OSC. México. https://drive.google.com/file/ d/rygxfehIE2fZtSxEAGL_8Hk53Y6ogZmx/view

CEMEFI(2020).ListadodeempresasqueobtuvieroneldistintivoESR 2020.https://www.cemefi.org/servicios/noticias/filantropicas/593I-empresas-grandes-que-obtuvieron-el-distintivo-esr-2020

Cruz, J., Mendoza-Gómez, J., y Rositas, JH. (2013). Responsabilidad social empresarial: Investigación empírica-exploratoria sobre los conceptos de RSE y RSU. Conferencia en el XVIII Congreso Internacional de Contaduría, Administración e Informática.

Del Prado, R. (2018). Ética de la comunicación. Gedisa.

Fortune (1995-2020). Global 500 ranking. Recuperado de: https:/fortune.com/global500/

Gómez, C. (2014). Branding: esencia del marketing moderno. Lid.

Fischer, L., y Espejo, J. (2004). Mercadotecnia. McGraw-Hill.

Gitlin, L. N., Lyons, K. J., \& Kolodner, E. (I994). A model to build collaborative research or educational teams of health professionals in gerontology. Educational Gerontology, 20(I), 15-34. Recuperado de https://psycnet.apa.org/record/1994-31298-o0I

Holstein, E. (s/f). Branding and Internet Marketing. GSB A Zurich.

Instituto Ethos \& SEBRAE (2003). Responsabilidade Social Empresarial para Micro e Pequenas Empresas. Passo a Passo.

Klein, N. (2005). No Logo: El poder de las marcas. Paidós.

Kotler, P., y Zaltman, G. (I97I) Social marketing: an approach to planned social change. Fournal of Marketing, 35(3), 3-I2.

Kotler, P., y Roberto, E. (1992). Marketing Social: estratégia para alterar o comportamento público. Campus.

Martorell, G. (2010, I6 de abril). Tres estrategias de diferenciación. Marketing Democrático. https:// marketingdemocratico.com/blogs/marketing-democratico/I0470257-tres-estrategias-de-diferenciacion

Namakforoosh, M. (1983). Mercadotecnia social: Teoría y aplicación. Limusa.

Ortiz, A. P. (20I0). La responsabilidad social empresarial como base de la estrategia competitiva de HZX. Tesis de grado. Universidad Javeriana. Colombia.

Paladino, M., y Mohan, A. (2002). Tendencias de la responsabilidad social empresaria en Argentina, Documento de Investigación. Escuela de Dirección y Negocios de la Universidad Austral.

Programa de las Naciones Unidas para el Desarrollo (PNUD). (I998). Informe sobre Desarrollo Humano 1998.

Reyno, M. (2006). Responsabilidad social empresarial (RSE) como ventaja competitiva, Tesis de maestría. Universidad Técnica Federico Santa María. 
S/A. (2004). El Pacto Global en Argentina. Documento de adbesión del sector privado argentino. http://www.pactoglobal.org.ar/userfiles/file/Documento\%2oBase\%20.pdf

Sandhusen, R. L. (2002). Mercadotecnia. Editorial Continental.

Servimedia \& Estudio de Comunicación (20II). Uso de internet y las berramientas 2.0 en los medios de comunicación. https://www.servimedia.es/sites/default/files/documentos/informe_medios internet_herramientas.pdf

Tratado de Libre Comercio de América de Norte (TLCAN 2020). Recuperado de http://www.sice. oas.org/trade/nafta_s/indicer.asp

Vizcay, G. (2017, I7 de mayo). Teflón: Otro asesino silencioso de Dupont. América Latina en Movimiento. https://www.alainet.org/es/articulo/185527

\section{HEMEROGR AFÍA}

Alea, G. (2007). Responsabilidad social empresarial. Su contribución al desarrollo sostenible. $R e$ vista Futuros, 5(17).

Calvo, J. M. (I996, junio 6). “Acusan a Nike de fabricar calzado de lujo explotando a niños de iı años. El País. https://elpais.com/diario/1996/06/07/sociedad/834098402_850215.html

Expansión (2014, 23 de diciembre). Las Io empresas más responsables en México. https://expansion.mx/negocios/20I4/I2/16/las-Io-empresas-mas-responsables-en-mexico

CNN, Money (I99I). Fortune 500 I99I. Recuperado de https://money.cnn.com/magazines/fortune/fortune 500_archive/full/I99I/Levy, I. (2020, 27 de enero) ¿Telmex a la quiebra? El Universal. https://www.eluniversal.com.mx/opinion/irene-levy/telmex-la-quiebra

López, A., Contreras, R., y Molina, R. (20II). La responsabilidad social empresarial como estrategia de competitividad en el sector alimentario. Cuadernos de Administración, 24(43), 26I-283.

López, A., y Contreras, R. (20IO). El concepto de responsabilidad social empresarial desde diversos enfoques teóricos.Ide@sCONCYTEG,5(58),420-433.

López, A. (20I0). La proactividad empresarial como elemento de competitividad. Ra Ximbai, 6(2), 303-3I2.

Roitstein,F. (2004). la responsabilidad social empresarial en argentina: tendencias y oportunidades. Academia. Revista Latinoamericana de Administración, (32), 5-28.

Rodríguez, I. (2020, I 8 de febrero). Exige el SAT a Walmart México pago de impuestos por más de io mil mdp.La Fornada. https://www.jornada.com.mx/ultimas/economia/2020/02/18/demandasat-a-walmart-mexico-pago-de-impuestos-por-mas-de-IO-5-mmdp-I74I.html

Sun. (20II, I6 de febrero). Retira Wal Mart productos milagro de tiendas. El Informador MX. https://www.informador.mx/Economia/Retira-Walmart-productos-milagro-de-tiendas-20II0216-0056.html

The Business week (I997). Best Sellers of I997. Recuperado de https:/www.bloomberg.com/news/ articles/1998-02-02/the-business-week-best-sellers-of-I997 


\section{VIDEOS}

Salvo los salva-Pelícanos (2008). [video]. YouTube. https://www.youtube.com/watch?v=CYt-6aEuBLQ

Klein. N. (20I2). No Logo: Marcas, globalización y resistencia. [video]. YouTube. https://www. youtube.com/watch?v=ZIIk6viG2Ss\&t=I3OIS

Esta obra está bajo Licencia Creative Commons Atribución-NoComercial-SinDerivadas 4.o Internacional. 